\title{
Effects of lung protective mechanical ventilation associated with permissive respiratory acidosis on regional extra- pulmonary blood flow in experimental ARDS
}

Rudolf Hering ${ }^{1,2^{*+}}$ (D), Stefan Kreyer ${ }^{1 *+}$ and Christian Putensen ${ }^{1}$

\begin{abstract}
Background: Lung protective mechanical ventilation with limited peak inspiratory pressure has been shown to affect cardiac output in patients with ARDS. However, little is known about the impact of lung protective mechanical ventilation on regional perfusion, especially when associated with moderate permissive respiratory acidosis. We hypothesized that lung protective mechanical ventilation with limited peak inspiratory pressure and moderate respiratory acidosis results in an increased cardiac output but unequal distribution of blood flow to the different organs of pigs with oleic-acid induced ARDS.
\end{abstract}

Methods: Twelve pigs were enrolled, 3 died during instrumentation and induction of lung injury. Thus, 9 animals received pressure controlled mechanical ventilation with a PEEP of $5 \mathrm{cmH}_{2} \mathrm{O}$ and limited peak inspiratory pressure $\left(17 \pm 4 \mathrm{cmH}_{2} \mathrm{O}\right)$ versus increased peak inspiratory pressure $\left(23 \pm 6 \mathrm{cmH}_{2} \mathrm{O}\right)$ in a crossover-randomized design and were analyzed. The sequence of limited versus increased peak inspiratory pressure was randomized using sealed envelopes. Systemic and regional hemodynamics were determined by double indicator dilution technique and colored microspheres, respectively. The paired student t-test and the Wilcoxon test were used to compare normally and not normally distributed data, respectively.

Results: Mechanical ventilation with limited inspiratory pressure resulted in moderate hypercapnia and respiratory acidosis $\left(\mathrm{PaCO}_{2} 71 \pm 12\right.$ vs. $46 \pm 9 \mathrm{mmHg}$, and pH $7.27 \pm 0.05$ vs. $7.38 \pm 0.04, p<0.001$, respectively), increased cardiac output (140 \pm 32 vs. $110 \pm 22 \mathrm{ml} / \mathrm{min} / \mathrm{kg}, \mathrm{p}<0.05)$ and regional blood flow in the myocardium, brain and spinal cord, adrenal and thyroid glands, the mucosal layers of the esophagus and jejunum, the muscularis layers of the esophagus and duodenum, and the gall and urinary bladders. Perfusion of kidneys, pancreas, spleen, hepatic arterial bed, and the mucosal and muscularis blood flow to the other evaluated intestinal regions remained unchanged.

Conclusions: In this porcine model of ARDS mechanical ventilation with limited peak inspiratory pressure resulting in moderate respiratory acidosis was associated with an increase in cardiac output. However, the better systemic blood flow was not uniformly directed to the different organs. This observation may be of clinical interest in patients, e.g. with cardiac, renal and cerebral pathologies.

Keywords: Cardiac output, Lung protective ventilation, Respiratory distress syndrome, Regional blood flow, Hemodynamics, Permissive hypercapnia

\footnotetext{
*Correspondence: Rudolf.Hering@ukb.uni-bonn.de; Stefan.Kreyer@ukb.uni-

bonn.de

${ }^{\dagger}$ Equal contributors

'Department of Anesthesia and Intensive Care Medicine, University Hospital

of Bonn, Bonn, Germany

Full list of author information is available at the end of the article
} International License (http://creativecommons.org/licenses/by/4.0/), which permits unrestricted use, distribution, and reproduction in any medium, provided you give appropriate credit to the original author(s) and the source, provide a link to the Creative Commons license, and indicate if changes were made. The Creative Commons Public Domain Dedication waiver (http://creativecommons.org/publicdomain/zero/1.0/) applies to the data made available in this article, unless otherwise stated. 


\section{Background}

Lung protective mechanical ventilation has been shown to improve the outcome of patients with ARDS [1]. Beyond the beneficial effects of limiting peak inspiratory airway pressures $\left(\mathrm{P}_{\mathrm{AW}}\right)$ and tidal volumes $\left(\mathrm{V}_{\mathrm{T}}\right)$ on the lungs by reducing stress and strain [2], alveolar cyclic recruitment-derecruitment [3], and pulmonary and systemic inflammatory responses [4] the impact of mechanical ventilation on the cardiovascular system is of growing interest. A group of experts recently stated that successfully managing the complex hemodynamics of the ventilated patient with ARDS is a key to patient survival [5]. Actually, ARDS and the strategy of mechanical ventilation not only affects the right heart and pulmonary vascular system [6] but also systemic blood flow [7-9]. Natalini et al. recently demonstrated that lung protective ventilation and moderate hypercapnia resulted in an improvement in cardiac output $(\mathrm{CO})$ and a decrease in oxygen extraction ratio in ARDS patients [10]. Extending these results of improved systemic hemodynamics to the regional vascular beds would be of great interest.

Because measuring organ and tissue perfusion directly is not feasible in critically ill patients, we conducted an experimental study using pigs with oleic-acid induced ARDS which were mechanically ventilated in a pressure controlled mode either with limited inspiratory $\mathrm{P}_{\mathrm{AW}}$ targeting moderate respiratory acidosis or increased inspiratory $\mathrm{P}_{\mathrm{AW}}$ targeting normal $\mathrm{pH}$. Regional perfusion of the myocardium, brain and spinal cord, kidneys, liver, spleen, pancreas, intestinal mucosa and muscularis, gall and urinary bladder, adrenal and thyroid glands were determined with colored microspheres. We hypothesized that limiting inspiratory $\mathrm{P}_{\mathrm{AW}}$ associated with moderate respiratory acidosis results in an increase in systemic blood flow but an unequal distribution of blood flows to different organs and tissues.

\section{Methods}

\section{Animal care approval}

The experiments were performed in accordance with German legislation governing animal studies and the International Association of Veterinary Editors' Consensus Author Guidelines on Animal Ethics and Welfare [11]. The study was reviewed by a governmental ethical committee and official permission was granted from the governmental animal care and use committee of the Regional Government of the District of Cologne, Germany (23.203.2-BN43, 15/00).

\section{Sample size}

We knew from previous studies of our group that the number of experimental animals was 12 including a drop-off rate of approximately 20 to $30 \%$ to detect differences in systemic and regional blood flows between different ventilatory settings with a given two-sided crossover design at a significance level of $5 \%(\alpha<0.05)$ with a probability of $80 \%(\beta=0.20)[12,13]$. Therefore, we a priori determined to use twelve pigs, mixed German breed, weighing 12 to $20 \mathrm{~kg}(16.3 \pm 1.83 \mathrm{~kg}$; mean \pm standard deviation (SD)).

\section{Instrumentation}

Before instrumentation, the animals were premedicated with intramuscular ketamine $(10 \mathrm{mg} / \mathrm{kg})$, xylazine hydrochloride $(2 \mathrm{mg} / \mathrm{kg})$, and placed supine on a heating pad to maintain core temperature at $38{ }^{\circ} \mathrm{C}$. Anesthesia was induced with intravenous sodium pentobarbital, a bolus of $10 \mathrm{mg} / \mathrm{kg}$, followed by infusion of $2 \mathrm{mg} / \mathrm{kg} / \mathrm{h}$ and $2 \mathrm{mg} / \mathrm{kg} / \mathrm{h}$ ketamine. The dosage of anesthetics was not changed until the end of the study, when the animals were killed using an overdose of pentobarbital and potassium chloride. To ensure adequate hydration $500 \mathrm{ml}$ Ringer solution was rapidly infused followed by an infusion rate of $5 \mathrm{ml} / \mathrm{kg} / \mathrm{h}$ throughout the study. Animals were intubated with a $7.5 \mathrm{~mm}$ internal diameter cuffed tracheal tube and ventilated using pressure controlled mechanical ventilation (Evita 2, Dräger Inc. Lübeck, Germany).

A 4-French thermistor-tipped pulmonary artery catheter (AI-07044; Arrow International, Inc., Reading, PA) was inserted through the right jugular vein. The left carotid artery was cannulated and a 4-Fr pigtail catheter (Duct-Occlud 147,420; pfm, Germany) was inserted into the left ventricle for injection of microspheres. A 7-French 3-lm catheter (OW-14703-E; Arrow International, Inc., Reading, PA) was placed in the abdominal aorta via the right femoral artery for pressure monitoring and blood sampling, and a 4-French thermistor-tipped fiberoptic catheter (Pulsiocath PV2024L, Pulsion Medical Systems, Munich, Germany) was advanced through the left femoral artery into the descending thoracic aorta. At the end of each experiment, the correct position of all catheters was verified by autopsy.

\section{Ventilatory measurements}

Gas flow was measured at the proximal end of the tracheal tube with a heated pneumotachograph (No.2, Fleisch, Lausanne, Switzerland) connected to a differential pressure transducer (Huba Control, Würenlos, Switzerland). Respiratory rate, $\mathrm{V}_{\mathrm{T}}$, and minute ventilation were derived from the integrated gas flow signal. Airway pressure was measured at the proximal end of the tracheal tube with a differential gas-pressure transducer (SMT, Munich, Germany). Data were sampled via an analog-digital converter (DT 2801-a; Data-Translation, Marlboro, MA) at sampling intervals of $3 \mathrm{~s}$, processed, and stored on a personal computer for offline-analysis. The software for data acquisition and evaluation was 
programmed using a commercially available software tool (Asyst ${ }^{\circ}$ 4.0; Keithly Asyst; Taunton, MA).

\section{Cardiovascular measurements}

Heart rate was obtained from the electrocardiogram. Systemic mean arterial pressure, central venous, mean pulmonary artery, and pulmonary artery occlusion pressures were transduced (Combitrans, Braun AG, Melsungen, Germany), recorded (CS/3, Datex, Helsinki, Finland), and stored on a personal computer. The transpulmonary double-indicator dilution method was used to estimate $\mathrm{CO}$ and intrathoracic blood volume as described previously [14]. Indocyanine green dye (Becton Dickinson, Cockeysville, MD, USA), $3 \mathrm{mg}$ dissolved in $6 \mathrm{ml}$ iced 5\% glucose solution was used as double-indicator and injected into the superior vena cava. Simultaneously dilution curves for dye and temperature were recorded in the aorta with the thermistor-tipped fiberoptic artery catheter. From these curves a computer (COLD-Z-021, Pulsion Medical Systems, Munich, Germany) estimated CO with the dyedilution method and determined the mean transit time of the first pass of the dye indicator for calculating intrathoracic blood volume $[14,15]$. Three determinations were performed at random moments during the ventilatory cycle and averaged. Standard formula were used to calculate systemic and pulmonary vascular resistance, and oxygen delivery. Values were indexed for body weight if appropriate.

\section{Blood gas analysis}

Arterial $\mathrm{PCO}_{2}$ and $\mathrm{pH}$ were determined with standard blood gas electrodes (ABL 510, Radiometer, Copenhagen, Denmark). Oxygen saturation $\left(\mathrm{SO}_{2}\right)$ of arterial and mixed venous blood, and total hemoglobin were determined by spectrophotmetry with a CO-oximeter (OSM3, Radiometer, Copenhagen, Denmark).

\section{Tissue blood flow measurements}

The colored microsphere technique was used to measure regional blood flow as described previously [12]. The polystyrene microspheres (Dye Track; Triton Technology, San Diego, CA) are coated with a single colored dye and are $15 \pm 0.3 \mu \mathrm{m} \mathrm{SD}$ in diameter. Red-, blue-, yellow-, white- or violet microspheres were used. Depending on the different absorbance characteristics of each color, 6 to 15 million microspheres suspended in 2 to $5 \mathrm{ml}$ of $0.9 \%$ saline solution containing $0.02 \%$ Tween 80 were used for each blood flow measurement. Starting $10 \mathrm{~s}$ before injection of the microspheres into the left ventricle and continuing for $120 \mathrm{~s}$ after injection was completed, two reference blood samples were withdrawn simultaneously from different lumina of the aortic catheter at a rate of $5 \mathrm{ml} / \mathrm{min}$ with a precision pump (AH 55-2226; Harvard Apparatus GmbH; March-Hugstetten, Germany). At the end of the experiments, animals were killed with sodium pentobarbital and potassium chloride. All organs and tissues to be evaluated were removed and cut into small pieces weighing $1-2.5 \mathrm{mg}$.

The trapped microspheres in each tissue- and blood samples were quantified by their dye content. After digestion of the tissue/blood with $4 \mathrm{M}$ potassium hydroxide microspheres were harvested on a polyester filter (pore size: $8 \mu \mathrm{m}$, diameter: $25 \mathrm{~mm}$, Nucleopore; Costar; Bodenheim; Germany) and washed with $2 \%$ Tween 80 and then with ethanol. The dye-cover was solved from the microspheres by using $200 \mu \mathrm{l}$ of dimethylformamide. Then, the dye-suspension was separated from the microspheres by centrifugation. Spectrophotometric analysis of mixed dye solutions was performed (Spectrophotometer DU64; Beckmann; Düsseldorf; Germany) and the composite spectrum of each dye solution was resolved into spectra of single constituents using a matrix inversion software package (Dye-Track; Triton Technologies; San Diego; CA). From spectrophotometric data tissue blood flow was calculated by the formula: Tissue blood flow $\left(\mathrm{ml} \cdot \mathrm{g}^{-1}\right.$. $\left.\min ^{-1}\right)=$ As. Vref. Aref ${ }^{-1}$. Ws ${ }^{-1}$ where As is absorbance of the tissue sample, Vref is the reference blood flow $\left(\mathrm{ml} \cdot \mathrm{min}^{-1}\right)$, Aref is the mean absorbance of both reference blood samples, and Ws is the weight of the tissue sample. For each organ, the respective median blood flow of all samples was calculated.

\section{Experimental protocol}

During instrumentation the animals were ventilated with a positive end-expiratory pressure set at $5 \mathrm{~cm} \mathrm{H}_{2} \mathrm{O}$, a peak inspiratory $\mathrm{P}_{\mathrm{AW}}$ set at $15 \mathrm{cmH}_{2} \mathrm{O}$, an inspiratory to expiratory ratio set at $1: 1$, and an inspiratory oxygen fraction $\left(\mathrm{FiO}_{2}\right)$ of $30 \%$. Experimental ARDS was induced by injection of $0.1 \mathrm{ml} / \mathrm{kg}$ purified oleic acid (J.T. Baker Inc., Phillipsburg, NJ) into the right atrial catheter over $30 \mathrm{~min}$. Additional $0.2 \mathrm{ml}$ increments of oleic acid were administered every 30 min until $\mathrm{PaO}_{2}$ was less than $50 \mathrm{mmHg}$. $\mathrm{FiO}_{2}$ was increased to avoid $\mathrm{SaO}_{2}$ below $85 \%$ and remained unchanged thereafter.

After induction of ARDS pigs were paralyzed using atracurium and mechanically ventilated using either an unchanged peak inspiratory $\mathrm{P}_{\mathrm{AW}}$ limited to $15 \mathrm{~cm} \mathrm{H}_{2} \mathrm{O}$ resulting in moderate respiratory acidosis or an increased peak inspiratory $\mathrm{P}_{\mathrm{AW}}$ to compensate for respiratory acidosis. The sequence of ventilation with limited or increased inspiratory $\mathrm{P}_{\mathrm{AW}}$ was randomized using sealed envelopes. During ventilation with limited inspiratory $\mathrm{P}_{\mathrm{AW}}$, respiratory rate and $\mathrm{FiO}_{2}$ were allowed to be adjusted to maintain $\mathrm{SaO}_{2} \geq 85 \%$ and $\mathrm{pH}$ above 7.25. If the respiratory rate had to be increased to an extent that inspiratory or expiratory flow curves did not return to zero at the end of inspiration or expiration indicating too short in- and deflation times the respiratory rate was 
reduced and $\mathrm{P}_{\mathrm{AW}}$ adjusted to increase $\mathrm{V}_{\mathrm{T}}$ in steps of $1 \mathrm{ml} / \mathrm{kg}$ to assure sufficient oxygenation $\left(\mathrm{SaO}_{2} \geq 85 \%\right)$ and decarboxylation ( $\mathrm{pH} \geq 7.25)$. Thirty minutes of equilibration were allowed for each intervention before measurements.

\section{Statistical analysis}

Values are presented either as mean \pm SD or as median (lower quartile; upper quartile). Data were evaluated for normal distribution with the Shapiro-Wilks W test. If values were normal distributed data obtained during the different ventilatory strategies were compared using the paired student $\mathrm{t}$-test, if data were not normally distributed data were compared using Wilcoxon test. To verify adequate mixing of microspheres in the blood circulation and even distribution of blood flow to the various organs after injection into the left ventricle, correlations were calculated between the numbers of microspheres trapped in the two reference blood samples as well as between blood flows to the right and left adrenal glands by using general linear regression. Differences were considered to be statistically significant if $\mathrm{p}$ was less than 0.05 .

\section{Results}

Of the 12 pigs included in the study one animal died during instrumentation due to refractory ventricular fibrillation after introducing the left ventricular pig-tail catheter, and two pigs died due to hypoxemia and right ventricular failure during induction of ARDS. Thus, data of 9 pigs were included into the analysis. Of these animals, 5 started with increased peak inspiratory $\mathrm{P}_{\mathrm{AW}}$ and 4 with limited inspiratory $\mathrm{P}_{\mathrm{AW}}$. Before measurements each of the ventilation settings reached its steady state.

Adequate mixing and distribution of injected microspheres was verified by highly significant correlations between the trapped number of microspheres in the two reference blood samples and the blood flow to the right and left adrenal gland $(r=0.98, p<0.0001)$.

Peak inspiratory $\mathrm{P}_{\mathrm{AW}}$ was increased to $23 \pm 6 \mathrm{~cm} \mathrm{H}_{2} \mathrm{O}$ during ventilation with increased $\mathrm{P}_{\mathrm{AW}}$ as compared to $17 \pm 4 \mathrm{~cm} \mathrm{H} \mathrm{H}_{2} \mathrm{O}$ during ventilation with limited $\mathrm{P}_{\mathrm{AW}}$. This resulted in significantly increased mean $\mathrm{P}_{\mathrm{AW}}, \mathrm{V}_{\mathrm{T}}$, minute ventilation, and $\mathrm{pH}$ and a decrease in $\mathrm{PaCO}_{2}$ during ventilation with higher inspiratory $\mathrm{P}_{\mathrm{AW}}$ $(p<0.001$, respectively). The increase in respiratory rate and $\mathrm{FiO}_{2}$ during ventilation with limited $\mathrm{P}_{\mathrm{AW}}$ to maintain $\mathrm{pH}$ above 7.25 and $\mathrm{SaO}_{2}$ above $85 \%$ were not statistically significant. During ventilation with limited $\mathrm{P}_{\mathrm{AW}}$ $\mathrm{PaO}_{2} / \mathrm{FiO}_{2}(p<0.05)$ decreased (Table 1).

Limiting $\mathrm{P}_{\mathrm{AW}}$ was associated with an increase in $\mathrm{CO}$, mean arterial and pulmonary arterial pressure, and $\mathrm{SvO}_{2}$ $(p<0.05$, respectively) while heart rate, central venous and pulmonary capillary wedge pressure, intrathoracic
Table 1 Ventilation and gas exchange variables

\begin{tabular}{|c|c|c|c|}
\hline & $\begin{array}{l}\text { Increased } \\
\mathrm{P}_{\mathrm{AW}}\end{array}$ & $\begin{array}{l}\text { Limited } \\
\mathrm{P}_{\text {AW }}\end{array}$ & \\
\hline $\mathrm{FiO}_{2}, \%$ & $66 \pm 25$ & $84 \pm 21$ & n.s. \\
\hline $\begin{array}{l}\text { Positive end-expiratory pressure, } \\
\mathrm{Cm} \mathrm{H}_{2} \mathrm{O}\end{array}$ & $5 \pm 0$ & $5 \pm 0$ & n.s. \\
\hline Peak inspiratory pressure, $\mathrm{cm} \mathrm{H}_{2} \mathrm{O}$ & $23 \pm 6$ & $17 \pm 4$ & $p<0.001$ \\
\hline Mean airway pressure, $\mathrm{cm} \mathrm{H}_{2} \mathrm{O}$ & $14.8 \pm 2.6$ & $11.4 \pm 1.8$ & $p<0.001$ \\
\hline $\mathrm{V}_{\mathrm{T}}, \mathrm{mL} \cdot \mathrm{kg}^{-1}$ & $9.5 \pm 3.0$ & $6.2 \pm 2.9$ & $p<0.001$ \\
\hline Minute ventilation, L. $\min ^{-1}$ & $4.9 \pm 0.8$ & $3.4 \pm 1.2$ & $p<0.001$ \\
\hline Respiratory rate, $\mathrm{min}^{-1}$ & $31 \pm 2$ & $34 \pm 3$ & n.s. \\
\hline $\mathrm{PaO}_{2} / \mathrm{FiO}_{2}, \mathrm{~mm} \mathrm{Hg}$ & $231 \pm 104$ & $182 \pm 90$ & $p<0.05$ \\
\hline $\mathrm{PaCO}_{2}, \mathrm{~mm} \mathrm{Hg}$ & $46 \pm 12$ & $71 \pm 9$ & $p<0.001$ \\
\hline $\mathrm{pH}_{\mathrm{a}}$ & $7.38 \pm 0.04$ & $7.27 \pm 0.05$ & $p<0.001$ \\
\hline
\end{tabular}

$P_{A W}$ airway pressure, $\mathrm{FiO}_{2}$ inspiratory fraction of oxygen, $V_{T}$ tidal volume. Values are presented as mean \pm standard deviation (SD); tested on a randomized basis; student t-test

blood volume, systemic and pulmonary vascular resistance, stroke volume, $\mathrm{SaO}_{2}$, oxygen delivery, and lactate remained unchanged (Table 2).

During ventilation with limited inspiratory $\mathrm{P}_{\mathrm{AW}}$ and moderate respiratory acidosis the increase in $\mathrm{CO}$ resulted in a significant increase in blood flow both to the subendocardial and subepicardial myocardium of the right and left ventricle while the ratio of subendocardial

Table 2 Cardiovascular variables

\begin{tabular}{|c|c|c|c|}
\hline & Increased $P_{\text {AW }}$ & Limited $P_{\text {AW }}$ & \\
\hline Heart rate, $\min ^{-1}$ & $115 \pm 35$ & $137 \pm 46$ & n.s. \\
\hline Mean arterial pressure, $\mathrm{mm} \mathrm{Hg}$ & $98 \pm 16$ & $117 \pm 16$ & $p<0.05$ \\
\hline $\begin{array}{l}\text { Mean pulmonary artery pressure, } \\
\mathrm{mmHg}\end{array}$ & $28 \pm 9$ & $32 \pm 11$ & $p<0.05$ \\
\hline $\begin{array}{l}\text { Pulmonary capillary wedge } \\
\text { pressure, } \mathrm{mm} \mathrm{Hg}\end{array}$ & $8 \pm 3$ & $7 \pm 3$ & n.s. \\
\hline Central venous pressure, $\mathrm{mm} \mathrm{Hg}$ & $12 \pm 5$ & $11 \pm 4$ & n.s. \\
\hline $\begin{array}{l}\text { Intrathoracic blood volume, } \\
\mathrm{mL} \cdot \mathrm{kg}^{-1}\end{array}$ & $20.7 \pm 4.2$ & $23.1 \pm 4.2$ & n.s. \\
\hline Cardiac output, $\mathrm{mL} . \mathrm{kg}^{-1} \cdot \mathrm{min}^{-1}$ & $110 \pm 22$ & $140 \pm 32$ & $p<0.05$ \\
\hline Stroke volume, $\mathrm{mL} . \mathrm{kg}^{-1}$. beat $^{-1}$ & $1.04 \pm 0.35$ & $1.08 \pm 0.25$ & n.s. \\
\hline $\begin{array}{l}\text { Systemic vascular resistance, } \\
\mathrm{mm} \mathrm{Hg} . \mathrm{kg} . \mathrm{min} . \mathrm{mL}^{-1}\end{array}$ & $2339 \pm 571$ & $2329 \pm 625$ & n.s. \\
\hline $\begin{array}{l}\text { Pulmonary vascular resistance, } \\
\mathrm{mm} \mathrm{Hg} . \mathrm{kg} . \mathrm{min} . \mathrm{mL}^{-1}\end{array}$ & $555 \pm 237$ & $532 \pm 218$ & n.s. \\
\hline Hemoglobin, g. $\mathrm{dL}^{-1}$ & $9.9 \pm 1.5$ & $10.7 \pm 1.5$ & $p<0.05$ \\
\hline $\mathrm{SaO}_{2},(\%)$ & $94 \pm 9$ & $90 \pm 11$ & n.s. \\
\hline $\mathrm{SvO}_{2}(\%)$ & $50 \pm 12$ & $62 \pm 13$ & $p<0.05$ \\
\hline Oxygen delivery, $\mathrm{mL} \cdot \mathrm{kg}^{-1} \cdot \mathrm{min}^{-1}$ & $13.0 \pm 2.7$ & $13.4 \pm 2.4$ & n.s. \\
\hline Lactate (mmol/l) & $1 \pm 0.4$ & $0.8 \pm 0.4$ & n.s. \\
\hline
\end{tabular}

$P_{A W}$ airway pressure, $\mathrm{SaO}_{2}$ arterial oxygen saturation, $\mathrm{SvO}_{2}$ mixed venous oxygen saturation. Values are presented as mean \pm standard deviation (SD); tested on a randomized basis; student t-test 
to subepicardial perfusion remained unchanged in both ventricles (Fig. 1). Regional blood flow to the brain and spinal cord also increased during ventilation with limited inspiratory $\mathrm{P}_{\mathrm{AW}}$ (Fig. 2). Similarly, blood flow increased to the adrenal $(p<0.01)$ and thyroid glands $(p<0.05)$ (Table 3$)$, the mucosal layers of the esophagus $(p<0.01)$ and jejunum $(p<0.05)$, the muscularis layers of the esophagus and duodenum $(p<0.05$, respectively), and the gall and urinary bladders $(p<0.01$, respectively) (Table 4). Perfusion of kidneys, pancreas, spleen, hepatic arterial bed, and the mucosa and muscularis layers of the other evaluated intestinal regions remained unchanged (Tables 3, 4).

For individual animal data see an additional file as an online supplement (Additional file 1).

\section{Discussion}

We examined the influence of lung protective mechanical ventilation in an experimental ARDS model on systemic and regional blood flow using the colored microspheres method. Mechanical ventilation with limited inspiratory $\mathrm{P}_{\mathrm{AW}}$ and moderate respiratory acidosis resulted in an increase in $\mathrm{CO}$, and variable changes in tissue perfusion.
The marked increase in adrenal perfusion indicates a sympatho-adrenal response to the moderate respiratory acidosis.

Our results confirm recent data on the interaction of lung protective mechanical ventilation and moderate respiratory acidosis on systemic hemodynamics [10] and extend these findings to the regional capillary and nutritional circulation. In our experimental animals limiting airway and intrathoracic pressures did not result in an increased preload as intrathoracic blood volume, central venous and pulmonary capillary wedge pressure remained unchanged. Along with the unchanged preload stroke volume only slightly increased. However, the combination of the slight increases in stroke volume and heart rate caused a significant increase in $\mathrm{CO}$, mean arterial and pulmonary arterial pressure. Although we did not determine sympatho-adrenergic and thyroid hormones the increase both in adrenal and thyroid blood flows during ventilation with limited inspiratory $\mathrm{P}_{\mathrm{AW}}$ may indicate that the augmented systemic and regional blood flow, at least in part, may have been caused by a hormonal response to moderate respiratory acidosis. In line with this observation hypercapnic acidosis has been previously reported to be
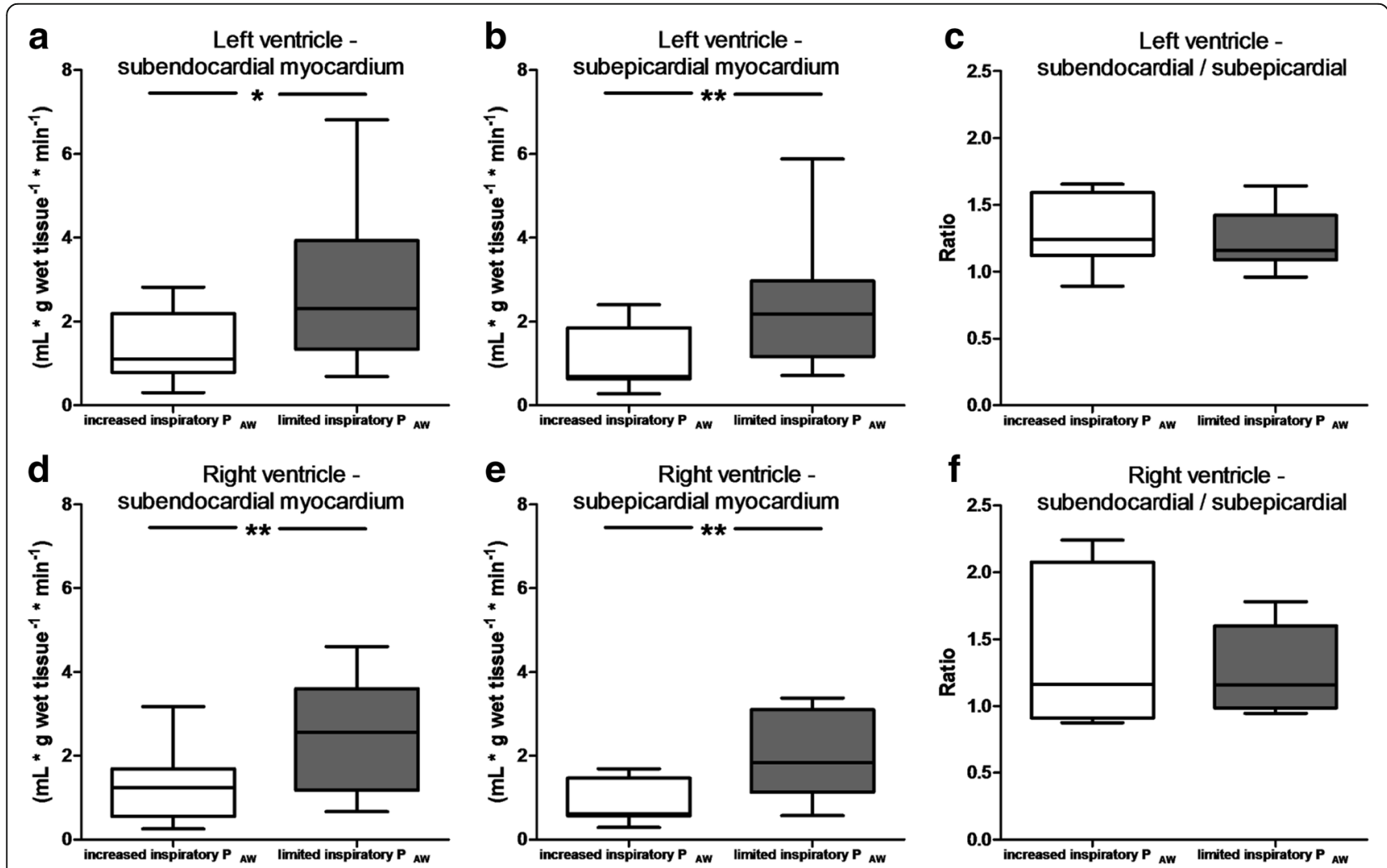

Fig. 1 Myocardial perfusion during mechanical ventilation with limited peak inspiratory pressure targeting permissive respiratory acidosis and increased peak inspiratory pressure targeting normal pH. Panel a: left ventricle - subendocardial myocardium; panel b: left ventricle - subepicardial myocardium; panel c: left ventricle - ratio of subendocardial to subendocardial perfusion; panel $\mathbf{d}$ : right ventricle - subendocardial myocardium; panel e: right ventricle - subepicardial myocardium; panel f: right ventricle - ratio of subendocardial to subendocardial perfusion; Boxes are median and 25/ 75 percentile, whiskers are 5/95\% percentile. ${ }^{*} p<0.05$ compared with increased $P_{\text {AW }}{ }^{* *} p<0.01$ compared with increased $P_{\text {AW }}$ 

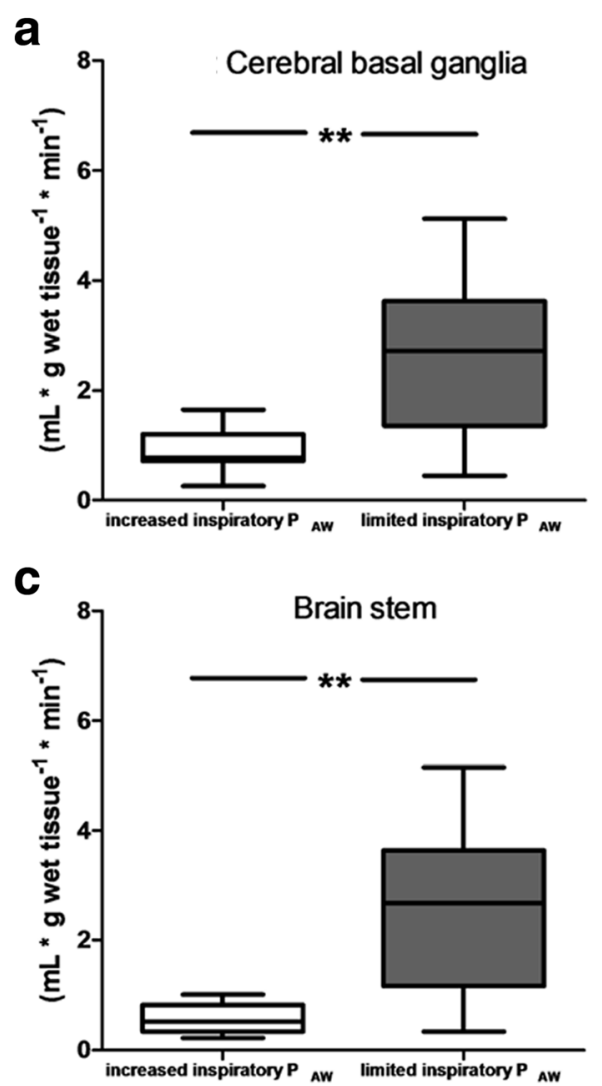

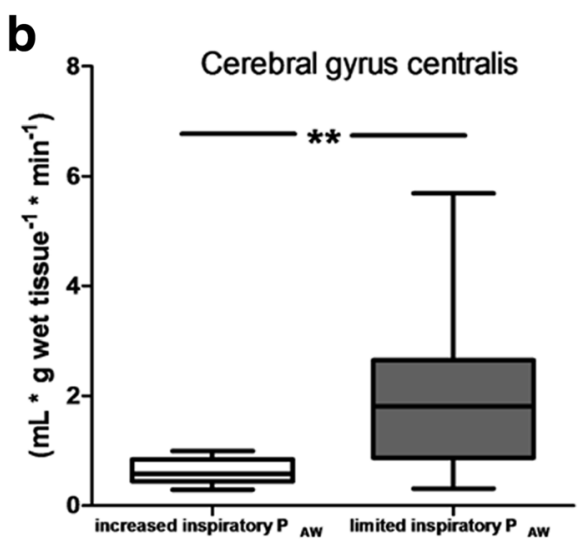

d

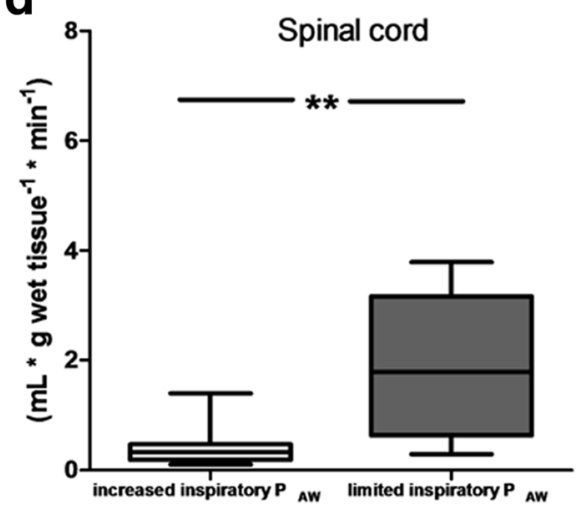

Fig. 2 Regional cerebral and spinal cord perfusion during mechanical ventilation with limited peak inspiratory pressure targeting permissive respiratory acidosis and increased peak inspiratory pressure targeting normal $\mathrm{pH}$. Panel a: cerebral basal ganglia; panel $\mathbf{b}$ : cerebral gyrus centralis; panel $\mathbf{c}$ : brain stem; panel d: spinal cord. Boxes are median and 25/75 percentile, whiskers are 5/95\% percentile. ${ }^{* *} p<0.01$ compared with increased $P_{\text {AW }}$

attributed to sympathetic activation and catecholamine release [16-18] which, at least in states of mild to moderate hypercapnic acidosis, overrides the direct depressant effects of carbon dioxide on myocardial cells $[18,19]$ and precapillary resistance vessels [20].

In parallel with the increase in systemic blood flow regional myocardial perfusion of the right and left ventricle was markedly increased. This is in agreement with previous in vitro and in vivo data obtained during hypercapnia in coronary vessels $[17,21]$ and reflects the

Table 3 Regional blood flow to solid organs ( $\mathrm{ml} \cdot \mathrm{g}$ wet tissue $-1 \cdot \min ^{-1}$ )

\begin{tabular}{llll}
\hline & Increased $P_{\text {AW }}$ & Limited $P_{\text {AW }}$ & \\
\hline Kidneys & $1.85(1.36 ; 2.12)$ & $2.02(1.53 ; 3.78)$ & n.s. \\
Adrenal glands & $1(0.76 ; 1.64)$ & $2.94(2.14 ; 7.89)$ & $p<0.01$ \\
Thyroidal gland & $0.16(0.09 ; 0.26)$ & $0.25(0.17 ; 0.68)$ & $p<0.05$ \\
Spleen & $1.58(1.31 ; 3.16)$ & $2.91(1.38 ; 6.32)$ & n.s. \\
Pancreas & $0.18(0.16 ; 0.32)$ & $0.23(0.20 ; 0.31)$ & n.s. \\
Liver (arterial vascular bed) & $0.5(0.22 ; 0.72)$ & $0.47(0.31 ; 0.95)$ & n.s. \\
\hline
\end{tabular}

$P_{A W}$ airway pressure. Values are presented as median (lower quartile; upper quartile); tested on a randomized basis, Wilcoxon matched pairs test
Table 4 Intestinal and urinary bladder blood flow ( $\mathrm{ml} \cdot \mathrm{g}$ wet tissue $^{-1} \cdot \min ^{-1}$ )

\begin{tabular}{llll}
\hline & Increased $P_{A W}$ & Limited $P_{A W}$ & \\
\hline $\begin{array}{l}\text { Esophagus (mucosa- } \\
\text { submucosa) }\end{array}$ & $0.18(0.10 ; 0.31)$ & $0.32(0.26 ; 0.41)$ & $p<0.01$ \\
Esophagus (muscularis-serosa) & $0.09(0.06 ; 0.14)$ & $0.16(0.15 ; 0.21)$ & $p<0.05$ \\
Stomach (mucosa-submucosa) & $0.16(0.14 ; 0.27)$ & $0.21(0.16 ; 0.29)$ & n.s. \\
Stomach (muscularis-serosa) & $0.05(0.03 ; 0.08)$ & $0.09(0.05 ; 0.11)$ & n.s. \\
Duodenum (mucosa- & $0.44(0.39 ; 0.52)$ & $0.58(0.3 ; 0.73)$ & n.s. \\
submucosa) & & & \\
Duodenum (muscularis-serosa) & $0.1(0.05 ; 0.17)$ & $0.16(0.08 ; 0.3)$ & $p<0.05$ \\
Jejunum (mucosa-submucosa) & $0.38(0.35 ; 0.56)$ & $0.62(0.39 ; 0.83)$ & $p<0.05$ \\
Jejunum (muscularis-serosa) & $0.04(0.01 ; 0.14)$ & $0.12(0.04 ; 0.14)$ & n.s. \\
lleum (mucosa-submucosa) & $0.27(0.2 ; 0.35)$ & $0.49(0.27 ; 0.9)$ & n.s. \\
lleum (muscularis-serosa) & $0.05(0.02 ; 0.13)$ & $0.07(0.03 ; 0.23)$ & n.s. \\
Colon (mucosa-submucosa) & $0.38(0.27 ; 0.49)$ & $0.45(0.36 ; 0.86)$ & n.s. \\
Colon (muscularis-serosa) & $0.02(0.01 ; 0.07)$ & $0.06(0.04 ; 0.11)$ & n.s. \\
Gall bladder & $0.34(0.18 ; 0.44)$ & $0.9(0.74 ; 2.04)$ & $p<0.01$ \\
Urinary bladder & $0.11(0.08 ; 0.41)$ & $0.2(0.16 ; 0.6)$ & $p<0.01$ \\
\hline
\end{tabular}

$P_{A W}$ airway pressure; Values are presented as median (lower quartile; upper quartile); tested on a randomized basis, Wilcoxon matched pairs test 
elevated metabolic demands of the myocardial pump associated with the increase in heart rate and CO. In our animals without coronary artery disease perfusion of both subepicardial and subendocardial perfusion rose to a similar extent and the transmural distribution of myocardial blood flow was not altered by the ventilatory strategy. In contrast, previous data obtained in animals with single-vessel coronary artery disease during severe hypercapnia of more than $120 \mathrm{mmHg}$ showed redistribution of blood flow from the subendocardial to subepicardial myocardium [21]. Therefore, clinicians should be aware of potential negative effects of hypercapnia in patients with multivessel coronary artery disease and/or myocardial insufficiency who are prone to myocardial ischemia.

Although maintaining normocapnia is essential in patients with intracranial hypertension even patients with intracranial pathologies may benefit from lung protective mechanical ventilation [22]. In our study ventilation with limited inspiratory $\mathrm{P}_{\mathrm{AW}}$ and moderate respiratory acidosis in the absence of intracranial hypertension resulted in a marked increase in cerebral and spinal perfusion. As we evaluated nutritional blood flow with the microsphere method our results may be of clinical relevance especially for patients at risk for cerebral and spinal ischemic lesions, patients with cerebral vasospasm due to subarachnoid hemorrhage and critically ill patients being prone for septic encephalopathy which has been claimed to be associated with an impairment of cerebral nutritional perfusion and metabolism [23, 24].

Mechanical ventilation may also compromise renal hemodynamics $[25,26]$. In our experimental animals, despite an increase in systemic blood flow, renal perfusion did not improve during ventilation with limited inspiratory $\mathrm{P}_{\mathrm{AW}}$ and moderate respiratory acidosis. This finding is consistent with observations of impaired renal blood flow due to renal vasoconstriction and an increase in renal vascular resistance in patients with hypercapnic respiratory failure $[27,28]$ and in patients with ARDS [29]. Therefore, during lung protective ventilation close monitoring of renal function is essential.

Mechanical ventilation has been suggested to contribute to the development of multiple organ dysfunction by potentiating adverse effects of underlying critical illness on splanchnic perfusion [30]. Because the mucosalsubmucosal and muscularis-serosal layers of the intestinal wall have different metabolic and oxygen requirements [31], with the mucosa-submucosa representing the layer with the highest demand, we measured blood flow to the different layers separately. Irrespective of the applied ventilatory strategy, mucosal-submucosal exceeded muscularis-serosal perfusion in our experimental animals, which is in accordance with previous investigations in different mammalian species [31] and reflects the high metabolic activity of the intestinal mucosa. While we found no significant change in the regional perfusion of the stomach, ileum and colon, the blood flow to the esophageal and jejunal mucosa-submucosa, the esophageal and duodenal muscularis-serosa, the gallbladder, and urinary bladder was increased during ventilation with limited inspiratory $\mathrm{P}_{\mathrm{AW}}$. Pancreatic perfusion remained unchanged and arterial hepatic perfusion even tended to decrease when inspiratory $\mathrm{P}_{\mathrm{AW}}$ was limited. This observation may, at least in part, have been caused by the intrinsic hepatic arterial buffer response [32] which counter-regulates changes in portal-venous and hepatic arterial blood flow to maintain overall hepatic blood flow constant.

During ventilation with limited inspiratory $\mathrm{P}_{\mathrm{AW}}$ the splenic perfusion also remained constant despite the increase in systemic blood flow. Although we were not able to determine the splenic weight during each ventilatory strategy the concomitant marked rise of the hemoglobin level suggests a splenic response to respiratory acidosis which has been shown to include a constriction of splenic vessels and depletion of erythrocytes from the splenic blood reservoir both in experimental animals [33] and humans [34].

\section{Methodology}

We used the colored microsphere method which is an established method for blood flow measurements [12, 35]. The theoretical basis of the microsphere technique is analogous to that of the indicator-dilution method and the number of particles impacted in a given tissue is proportional to the volume of particle-containing blood perfusing that tissue. A major advantage of this method is its ability to quantitate nutritive blood flow to individual tissue regions which may be as small as separate layers of the intestinal wall [12] and that measurements are possible without surgical interventions such as implantation of electromagnetic flow probes which per se may alter regional perfusion. The validity of using microspheres to study regional blood flow distribution is based on adequate mixing of injected microspheres and even distribution to the various parts of the body. This was demonstrated in our study by the close correlation between the numbers of microspheres trapped in the reference blood samples from different sites in the aorta and nearly identical blood flows to both adrenal glands.

\section{Study limitations}

Because direct measurement of regional perfusion is not possible in critical ill patients we used a porcine model of ARDS which was induced with oleic acid. Therefore, our findings are not generalizable to humans and may vary based on different etiologies of ARDS. Limiting inspiratory $\mathrm{P}_{\mathrm{AW}}$ resulted in a decrease in minute ventilation and moderate permissive respiratory acidosis which 
is common in daily clinical practice. Consequently, due to the combined variation of intrathoracic pressures and acid base balance we were not able to separate the effects of both parameters on the systemic and regional blood flows. Although gas exchange variables stabilized during equilibration periods before each measurement the time limits of our study probably were too short to elucidate potential carry over effects due to the crossover design, e.g. long-term effects on a transcriptional/ translational level and slow acting counter-regulatory effects. At last, as we did not determine any vasoactive hormones, we could only speculate on additional hormonal effects on systemic and regional blood flows by the observation of marked increases in adrenal and thyroid perfusion.

\section{Conclusions}

In this porcine model of ARDS mechanical ventilation with limited inspiratory $\mathrm{P}_{\mathrm{AW}}$ associated with moderate respiratory acidosis resulted in an increase in systemic blood flow which was not uniformly directed to the regional vascular beds. Our results may add some physiological understanding to the complex field of heart-lung interactions and its' effects on regional perfusion and may promote further clinical investigation with special attention to subgroups of patients, e.g. with cardiac, renal and cerebral pathologies.

\section{Additional file}

Additional file 1: Individual animal data. Excel file with individual data of all animals (ventilation, gas exchange, cardiovascular, and regional blood flow variables). (XLSX $49 \mathrm{~kb}$ )

\section{Abbreviations}

ARDS: Acute respiratory distress syndrome; $\mathrm{CO}$ : Cardiac output; $\mathrm{FiO}_{2}$ : Inspiratory oxygen fraction; $P_{\text {AW: }}$ : Airway pressure; $V_{\mathrm{T}}$ : Tidal volume

\section{Acknowledgements}

The authors thank Mr. Mario Sitzia, Department of Experimental Surgery, University of Bonn, Germany, for his excellent technical support during the experiments.

\section{Funding}

No external funding was required for this research.

\section{Availability of data and materials}

The datasets generated and analysed during the current study are available from the corresponding author on reasonable request.

\section{Authors' contributions}

$\mathrm{RH}$ and SK equally contributed to the study. $\mathrm{RH}$ and SK participated in the design of the study, conducted the study, performed the statistical analyses, and wrote the manuscript. CP participated in the design of the study and revised the manuscript. All authors read and approved the final version of the manuscript.

\section{Ethics approval}

The experiments were performed in accordance with German legislation governing animal studies and the International Association of Veterinary Editors' Consensus Author Guidelines on Animal Ethics and Welfare [11]. The study was reviewed by a governmental ethical committee and official permission was granted from the governmental animal care and use committee of the Regional Government of the District of Cologne, Germany (23.203.2-BN43, 15/00).

Consent for publication

Not applicable.

Competing interests

The authors declare that they have no competing interests.

\section{Publisher's Note}

Springer Nature remains neutral with regard to jurisdictional claims in published maps and institutional affiliations.

\section{Author details}

${ }^{1}$ Department of Anesthesia and Intensive Care Medicine, University Hospital of Bonn, Bonn, Germany. 'Department of Anesthesia, Intensive Care, Emergency and Pain Medicine, Kreiskrankenhaus Mechernich GmbH, Mechernich, Germany.

Received: 26 June 2017 Accepted: 19 October 2017

Published online: 27 October 2017

\section{References}

1. ARDS network. Ventilation with lower tidal volumes as compared with traditional tidal volumes for acute lung injury and the acute respiratory distress syndrome. The acute respiratory distress syndrome network. $N$ Engl J Med. 2000;342:1301-8.

2. Protti A, Cressoni M, Santini A, et al. Lung stress and strain during mechanical ventilation: any safe threshold? Am J Respir Crit Care Med. 2011;183:1354-62.

3. Bruhn A, Bugedo D, Riquelme F, et al. Tidal volume is a major determinant of cyclic recruitment-derecruitment in acute respiratory distress syndrome. Minerva Anestesiol. 2011;77:418-26.

4. Ranieri VM, Suter PM, Tortorella C, et al. Effect of mechanical ventilation on inflammatory mediators in patients with acute respiratory distress syndrome: a randomized controlled trial [see comments]. JAMA. 1999;282:54-61.

5. Vieillard-Baron A, Matthay M, Teboul $\mathrm{J}$, et al. Experts' opinion on management of hemodynamics in ARDS patients: focus on the effects of mechanical ventilation. Intensive Care Med. 2016:42:739-49.

6. Mekontso DA, Boissier F, Charron C, et al. Acute cor pulmonale during protective ventilation for acute respiratory distress syndrome: prevalence, predictors, and clinical impact. Intensive Care Med. 2016:42:862-70.

7. Carvalho CR, Barbas CS, Medeiros DM, et al. Temporal hemodynamic effects of permissive hypercapnia associated with ideal PEEP in ARDS. Am J Respir Crit Care Med. 1997;156:1458-66.

8. Kiiski R, Takala J, Kari A, Milic-Emili J. Effect of tidal volume on gas exchange and oxygen transport in the adult respiratory distress syndrome. Am Rev Respir Dis. 1992;146:1131-5.

9. Pinsky MR. The hemodynamic consequences of mechanical ventilation: an evolving story [see comments]. Intensive Care Med. 1997:23:493-503.

10. Natalini G, Minelli C, Rosano A, et al. Cardiac index and oxygen delivery during low and high tidal volume ventilation strategies in patients with acute respiratory distress syndrome: a crossover randomized clinical trial. Crit Care. 2013;17:R146.

11. Institute of Laboratory Animal Resources CoLSNRC. Guide for the care and use of laboratory animals. Washington,D.C: National Academy Press; 1996.

12. Hering $R$, Viehofer $A$, Zinserling J, et al. Effects of spontaneous breathing during airway pressure release ventilation on intestinal blood flow in experimental lung injury. Anesthesiology. 2003:99:1137-44.

13. Kreyer S, Muders T, Luepschen $\mathrm{H}$, et al. Pumpless extracorporeal $\mathrm{CO}(2)$ removal restores normocapnia and is associated with less regional perfusion in experimental acute lung injury. Acta Anaesthesiol Scand. 2014;58:52-60.

14. Hoeft A. Transpulmonary indicator dilution: an alternative approach for hemodynamic monitoring. In: Vincent $J$, editor. Yearbook of intensive care and emergency medicine. 1st ed. Berlin, Heidelberg, New York: Springer; 1995.

15. Godje O, Peyerl M, Seebauer T, Dewald O, Reichart B. Reproducibility of double indicator dilution measurements of intrathoracic blood volume compartments, extravascular lung water, and liver function. Chest. 1998; 113:1070-7

16. Brofman JD, Leff AR, Munoz NM, Kirchhoff C, White SR. Sympathetic secretory response to hypercapnic acidosis in swine. J Appl Physiol. 1990;69:710-7. 
17. Akca O. Optimizing the intraoperative management of carbon dioxide concentration. Curr Opin Anaesthesiol. 2006;19:19-25.

18. Walley KR, Lewis TH, Wood LD. Acute respiratory acidosis decreases left ventricular contractility but increases cardiac output in dogs. Circ Res. 1990; 67:628-35.

19. Tang WC, Weil MH, Gazmuri RJ, Bisera J, Rackow EC. Reversible impairment of myocardial contractility due to hypercarbic acidosis in the isolated perfused rat heart. Crit Care Med. 1991;19:218-24.

20. Daugherty RMJ, Scott JB, Dabney JM, Haddy FJ. Local effects of $\mathrm{O} 2$ and $\mathrm{CO} 2$ on limb, renal, and coronary vascular resistances. Am J Phys. 1967;213:1102-10.

21. Arellano R, Jiang MT, O'Brien W, et al. Acute graded hypercapnia increases collateral coronary blood flow in a swine model of chronic coronary artery obstruction. Crit Care Med. 1999;27:2729-34.

22. Mazzeo AT, Fanelli V, Mascia L. Brain-lung crosstalk in critical care: how protective mechanical ventilation can affect the brain homeostasis. Minerva Anestesiol. 2013;79:299-309.

23. Burkhart CS, Siegemund M, Steiner LA. Cerebral perfusion in sepsis. Crit Care. 2010;14:215

24. Bowton DL, Bertels NH, Prough DS, Stump DA. Cerebral blood flow is reduced in patients with sepsis syndrome. Crit Care Med. 1989;17:399-403.

25. Steinhoff $H$, Falke K, Schwarzhoff W. Enhanced renal function associated with intermittent mandatory ventilation in acute respiratory failure. Intensive Care Med. 1982;8:69-74.

26. Annat G, Viale JP, Bui XB, et al. Effect of PEEP ventilation on renal function, plasma renin, aldosterone, neurophysins and urinary $\mathrm{ADH}$, and prostaglandins. Anesthesiology. 1983;58:136-41.

27. Howes TQ, Deane CR, Levin GE, Baudouin SV, Moxham J. The effects of oxygen and dopamine on renal and aortic blood flow in chronic obstructive pulmonary disease with hypoxemia and hypercapnia. Am J Respir Crit Care Med. 1995;151:378-83.

28. Sharkey RA, Mulloy EM, O'Neill SJ. The acute effects of oxygen and carbon dioxide on renal vascular resistance in patients with an acute exacerbation of COPD. Chest. 1999:115:1588-92.

29. Hering R, Peters D, Zinserling J, Wrigge $H$, von Spiegel T, Putensen C. Effects of spontaneous breathing during airway pressure release ventilation on renal perfusion and function in patients with acute lung injury. Intensive Care Med. 2002;28:1426-33.

30. Putensen $C$, Wrigge $H$, Hering R. The effects of mechanical ventilation on the gut and abdomen. Curr Opin Crit Care. 2006;12:160-5.

31. Granger DN, Richardson PD, Kvietys PR, Mortillaro NA. Intestinal blood flow. Gastroenterology. 1980;78:837-63.

32. Lautt WW. Mechanism and role of intrinsic regulation of hepatic arterial blood flow: hepatic arterial buffer response. Am J Phys. 1985;249:G549-56.

33. Ramirez J, Totapally BR, Hon E, et al. Oxygen-carrying capacity during 10 hours of hypercapnia in ventilated dogs. Crit Care Med. 2000;28:1918-23.

34. Richardson MX, Engan HK, Lodin-Sundstrom A, Schagatay E. Effect of hypercapnia on spleen-related haemoglobin increase during apnea. Diving Hyperb Med. 2012;42:4-9.

35. Kowallik P, Schulz R, Guth BD, et al. Measurement of regional myocardial blood flow with multiple colored microspheres. Circulation. 1991;83:974-82.

\section{Submit your next manuscript to BioMed Central and we will help you at every step:}

- We accept pre-submission inquiries

- Our selector tool helps you to find the most relevant journal

- We provide round the clock customer support

- Convenient online submission

- Thorough peer review

- Inclusion in PubMed and all major indexing services

- Maximum visibility for your research

Submit your manuscript at www.biomedcentral.com/submit 